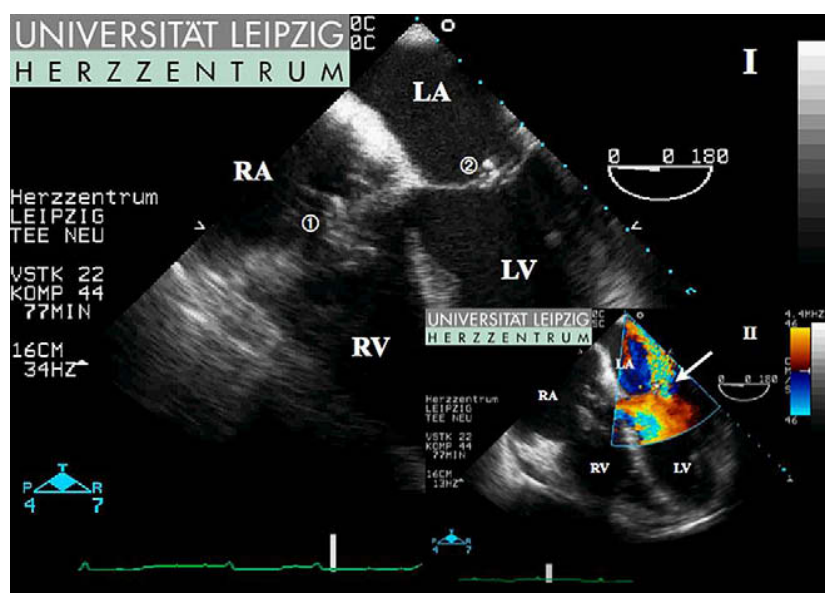

FIGURE 2. Severe endocarditis of the tricuspid valve ( 1 ) and suspected endocarditis of the mitral valve with moderate insufficiency (2). $L A$, Left atrium; $R A$, right atrium; $L V$, left ventricle; $R V$, right ventricle.

with E. faecalis and G. morbillorum, and (2) all cardiac valves were replaced in 1 operation. To the best of our knowledge, the current report is the first to describe successful quadruple valve replacement for acute endocarditis.

E. faecalis is known to cause endocarditis, as is G. morbillorum, but a simultaneous infection with both organisms has been described only once. ${ }^{1}$ Infection with E. faecalis can be extensive, as reported by Krake and colleagues ${ }^{2}$ in a patient with involvement of all cardiac valves. The patient in this case report did not undergo surgical treatment and subsequently died of sepsis. ${ }^{2}$

Involvement of all 4 heart valves can be observed with in other pathologic processes. Chiappini and colleagues ${ }^{3}$ reported on a patient with severe dysfunction of all valves secondary to carcinoid spread from the ileum. Their patient underwent valve replacement (tricuspid, pulmonary) and valve repair (aortic, mitral) with a good recovery. Hossack and colleagues ${ }^{4}$ also reported on a patient with rheumatic involvement of all valves treated with repeated operations, with a good long-term outcome. These 2 cases demonstrate that quadruple valve surgery can be successfully performed. Although the addition of pulmonary valve replacement adds to the complexity of the operation, previous investigators have demonstrated good long-term results with triple valve surgery. ${ }^{5}$

Our patient made a good recovery from a large and complex operation, despite several severe comorbidities before surgery and his complicated postoperative course. We think his recovery justifies such aggressive surgical therapy in selected patients with quadruple valve disease.

\section{CONCLUSIONS}

Replacement of all 4 heart valves in 1 operation is feasible in selected patients. Even in patients with endocarditis, a satisfactory outcome can be achieved.

\section{References}

1. Abboud R, Friart A. Two cases of isolated tricuspid endocarditis following colonic intervention. Acta Clin Belg. 1995;50:242-5

2. Krake PR, Zaman F, Tandon N. Native quadruple-valve endocarditis caused by Enterococcus faecalis. Tex Heart Inst J. 2004;31:90-2.

3. Chiappini B, Noirhomme P, Verhelst R, El Khoury G. Quadruple valve involvement in a patient with severe carcinoid heart disease. J Card Surg. 2006;21: 599-600.

4. Hossack KF, Hopeman AR, Sutherland EW 3rd. Long-term follow-up of a patien with quadruple valve replacement. Tex Heart Inst J. 1987;14:315-7.

5. Alsoufi B, Rao V, Borger MA, Maganti M, Armstrong S, Feindel CM, et al. Shortand long-term results of triple valve surgery in the modern era. Ann Thorac Surg. 2006;81:2172-8.

\title{
A new miniaturized cardiopulmonary bypass system reduces transfusion requirements during neonatal cardiac surgery: Initial experience in 13 consecutive patients
}

\author{
Andreas Koster, MD, ${ }^{\mathrm{a}}$ Michael Huebler, MD, ${ }^{\mathrm{b}}$ Wolfgang Boettcher, ECCP, ${ }^{\mathrm{c}}$ Mathias Redlin, MD, ${ }^{\mathrm{a}}$ Felix Berger, MD, ${ }^{\mathrm{d}}$ and \\ Roland Hetzer, MD, ${ }^{\mathrm{b}}$ Berlin, Germany
}

The potential detrimental effects of the transfusion of autologous blood products on patients' outcome is increasingly appreciated. ${ }^{1,2}$ This has promoted strategies to reduce the

\footnotetext{
From the Department of Anesthesia ${ }^{a}$ Department of Cardiovascular and Thoracic Surgery, ${ }^{\mathrm{b}}$ Department of Perfusion, ${ }^{\mathrm{c}}$ and Department of Cogenital Heart Disease, ${ }^{\mathrm{d}}$ Deutsches Herzzentrum Berlin, Berlin, Germany.

The study was supported by the "Deutsches Herzzentrum Berlin.",

Received for publication Jan 8, 2008; revisions received Feb 20, 2008; accepted for publication March 18, 2008.
}

consumption of donor blood products, as well as investigations assessing lower "critical" hemoglobin values as a trigger for transfusions. ${ }^{3}$ However, particularly in small infants

\footnotetext{
Address for reprints: Andreas Koster, MD, Department of Anesthesia, Deutsches Herzzentrum Berlin, Augustenburger Platz 1, D-13353 Berlin, Germany (E-mail: koster@dhzb.de).

J Thorac Cardiovasc Surg 2009; 137:1565-8

$0022-5223 / \$ 36.00$

Copyright (c) 2009 by The American Association for Thoracic Surgery doi:10.1016/j.jtcvs.2008.03.056
} 
and neonates, the goal of transfusion-free cardiovascular surgery is usually limited by the extreme hemodilution caused by the relatively large priming volume of the cardiopulmonary bypass (CPB) system. During recent years, we have demonstrated that implementation of small components in the CPB circuit resulting in reduction of the CPB priming volume facilitated transfusion-free cardiovascular surgery in selected cases in neonates and small infants. ${ }^{4}$ Here we report our first experiences with a new miniature oxygenator and arterial filter system that further significantly reduces the priming volume of our neonatal $\mathrm{CPB}$ circuit.

\section{CLINICAL SUMMARY}

After approval by the local ethics committee and having obtained informed consent from the parents, we analyzed the data of 13 consecutive neonates (age $\leq 28$ days) who underwent cardiovascular surgery at our institution with the new CPB setup.

The new CPB system differs from our previously described setup on the mast-mounted pediatric console (Stöckert, Munich, Germany) by incorporation of the KIDS D100 oxygenator (Sorin, Mirandola, Italy) and the new arterial filter line D 130 (Sorin; Figure 1). ${ }^{4}$ Using this modified setup, the total priming volume of the CPB was reduced from 200 $\mathrm{mL}$ to $110 \mathrm{~mL}$. The surgical procedures and baseline data are detailed in Table 1. In all procedures a pump flow of 2.5 to 3 $\mathrm{L} / \mathrm{m}^{2}$ was maintained with the aid of vacuum-assisted drainage. In accordance with departmental standards, during $\mathrm{CPB}$, the critical hemoglobin value was $7 \mathrm{~g} / \mathrm{dL}$, and after $\mathrm{CPB}$, under the conditions of normothermia $\left(36^{\circ} \mathrm{C}-37^{\circ} \mathrm{C}\right)$ and normovolemia (atrial filling pressures, $8-12 \mathrm{~mm} \mathrm{Hg}$ ) and depending on the overall clinical situation of the patient, the hemoglobin value was 8 to $10 \mathrm{~g} / \mathrm{dL}$ in patients undergoing anatomic correction and 12 to $16 \mathrm{~g} / \mathrm{dL}$ in cyanotic patients undergoing palliative procedures. During the operation, regional oxygenation was monitored by means of near-infrared spectroscopy optodes placed on the forehead and leg. After CPB, the circuit was flushed with saline, and the volume was processed with a small-volume cell bowl (55 mL; Dideco, Mirandola, Italy).

The results are shown in Table 1 . The clinical course of all patients was uneventful. In all patients regional tissue oxygenation obtained through near-infrared spectroscopy was comparable with that in other uneventful procedures performed at our institution, and the tissue oxygenation index ranged between $75 \%$ and $45 \% .^{5}$ In all patients the hemoglobin values obtained after initiation of CPB approximated the values calculated before CPB. Because of low baseline hemoglobin values, in 2 patients the CPB was primed with packed red blood cells. In 5 further patients, administration of packed red blood cells was necessary during the further course of CPB. Overall, transfusions were necessary in 7 patients, whereas in 6 patients (Figure 2) the operation could be performed without the use of any blood products. In only

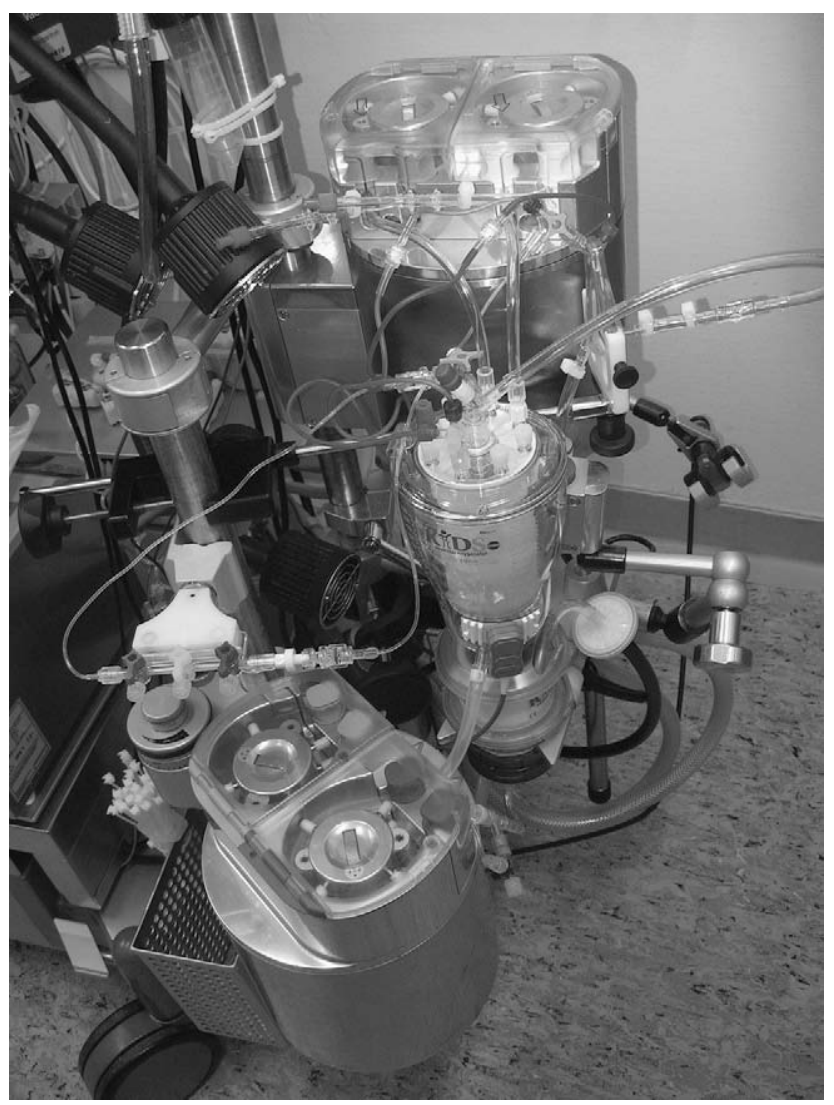

FIGURE 1. The miniaturized CPB system. The double roller pumps are mast-mounted remote pump heads that can be positioned almost unrestrictedly. The arterial pump is placed very close to the outlet of the venous reservoir and to the inlet of the oxygenator/heat exchanger (priming volume, 31 $\mathrm{mL}$ ). The arterial line filter has a priming volume of $16 \mathrm{~mL}$. The cardiotomy suction pumps are in proximity to the cardiotomy reservoir inlets. All tubing connections have internal diameters of $3 / 16$ inch, with the exception of the segment of the arterial pump, which consists of 1/4-inch silicone tubing.

one of these patients was the hemoglobin value in the critical area of $7 \mathrm{~g} / \mathrm{dL}$; in all other patients it was maintained in the range of 8 to $10 \mathrm{~g} / \mathrm{dL}$ (Figure 2). However, 4 of these patients received transfusions during the further course. This is attributable to a postoperative decrease in the hemoglobin value as a result of postoperative drainage or blood sampling.

\section{DISCUSSION}

The current data demonstrate that with the use of a miniature CPB system, the goal of transfusion-free cardiovascular surgery can be accomplished, even in the smallest neonates undergoing complex CPB procedures. This particularly applies to the subgroup of patients undergoing corrective procedures because $70 \%$ of these patients required no transfusions, whereas all patients with a cyanotic malformation who underwent palliative procedures received transfusions. 
TABLE 1. Surgical procedures and clinical data

\begin{tabular}{|c|c|c|c|c|c|c|c|c|c|c|}
\hline Diagnosis & Procedure & $\begin{array}{c}\text { Pall } \\
\text { iation }\end{array}$ & $\begin{array}{l}\text { Weight } \\
\text { (kg) }\end{array}$ & $\begin{array}{c}\text { Hb } \\
\text { before } \\
\text { CPB (g/dL) }\end{array}$ & $\begin{array}{c}\text { Calculated } \\
\text { Hb } \\
\text { (new/old* } \\
\text { CPB; g/dL) }\end{array}$ & $\begin{array}{c}\text { Hb on } \\
\text { CPB } \\
(\mathrm{g} / \mathrm{dL})\end{array}$ & $\begin{array}{c}\text { Duration } \\
\text { of CPB (min) }\end{array}$ & $\begin{array}{c}\text { Temperature } \\
\left({ }^{\circ} \mathbf{C}\right)\end{array}$ & $\begin{array}{c}\text { Hb after } \\
\text { operation }(g / d L)\end{array}$ & Transfusion \\
\hline TGA & $\begin{array}{l}\text { Arterial } \\
\text { switch } \\
\text { operation }\end{array}$ & No & 1.7 & 13.1 & $7.8 / 5.3$ & 7.4 & 137 & 26 & 11.0 & No \\
\hline TA, VSD & $\begin{array}{l}\text { DKS } \\
\text { procedure }\end{array}$ & Yes & 2.9 & 11.1 & $7.7 / 5.8$ & 8.3 & 74 & 30 & 13.7 & $1 \mathrm{PRBC} 1 \mathrm{FFP}$ \\
\hline PA & RVOT patch & Yes & 3 & 11.4 & $8 / 6.0$ & 6.4 & 98 & 24 & 13.0 & $1 \mathrm{PRBC} 1 \mathrm{FFP}$ \\
\hline TGA & $\begin{array}{l}\text { Arterial } \\
\quad \text { switch } \\
\text { operation }\end{array}$ & No & 3 & 12.0 & $8.4 / 6.2$ & 8.3 & 103 & 28 & 10.2 & No \\
\hline HLHS & $\begin{array}{l}\text { Norwood } \\
\quad \text { I procedure }\end{array}$ & Yes & 3.2 & 13.9 & $10 / 7.3$ & 10.6 & 121 & 12 & 14.5 & $\begin{array}{c}1 \text { PRBC } 1 \text { FFP } \\
1 \text { RDPC }\end{array}$ \\
\hline PA, VSD & $\begin{array}{l}\text { VSD closure, } \\
\text { AP shunt }\end{array}$ & Yes & 3.3 & 13.3 & $9.4 / 7.4$ & 14.8 & 43 & 34 & 14.1 & $1 \mathrm{PRBC} 1 \mathrm{FFP}$ \\
\hline TAPVD & Correction & No & 2.9 & 11.5 & $9.7 / 5.9$ & 8.6 & 70 & 16 & 10.0 & No \\
\hline HAA & Correction & No & 3.3 & 15 & $10.1 / 7.8$ & 10.0 & 130 & 16 & 11.5 & No \\
\hline $\begin{array}{l}\text { HAA, } \\
\text { VSD }\end{array}$ & Correction & No & 2.1 & 12.5 & $9.0 / 4.0$ & 10.1 & 117 & 14 & 12.7 & 1 PRBC 1 FFP \\
\hline $\begin{array}{l}\text { HAA, } \\
\text { ASD }\end{array}$ & Correction & No & 2.8 & 14.4 & $9.8 / 7.0$ & 8.8 & 108 & 20 & 11.0 & Yes \\
\hline $\begin{array}{l}\text { TGA, } \\
\text { VSD }\end{array}$ & $\begin{array}{l}\text { Arterial } \\
\text { switch } \\
\text { operation, } \\
\text { VSD closure }\end{array}$ & No & 3.1 & 12.3 & $8.7 / 6.2$ & 9.5 & 108 & 24 & 8.2 & No \\
\hline $\begin{array}{l}\text { HAA, } \\
\text { VSD, } \\
\text { ASD }\end{array}$ & $\begin{array}{l}\text { Patch } \\
\quad \text { correction }\end{array}$ & No & 2.4 & 16.0 & $10.3 / 7.2$ & 9.7 & 133 & 12 & 13.8 & $\begin{array}{c}1 \mathrm{PRBC} 1 \mathrm{FFP} \\
1 \mathrm{RDPC}\end{array}$ \\
\hline $\begin{array}{l}\text { IAA, } \\
\text { VSD }\end{array}$ & $\begin{array}{l}\text { Resection, } \\
\text { correction }\end{array}$ & No & 4.1 & 14.5 & $9.4 / 8.0$ & 10.1 & 129 & 14 & 13.1 & No \\
\hline
\end{tabular}

Our formerly used small neonatal CPB setup requires a priming volume of only $200 \mathrm{~mL}$, which is fairly low compared with currently published data with priming volumes of around $330 \mathrm{~mL}$. $^{6,7}$ Based on the hemoglobin values before initiation of $\mathrm{CPB}$, use of this system would have required a sanguine priming volume in almost all of the patients (Table 1), and the probability of need for transfusions during the further course of the operation in the remaining patients would have been high. Therefore we conclude that the new CPB setup considerably contributed to the success in the 6 patients.

Our data provide convincing evidence that stringent downsizing of the CPB system, while incorporating all standard safety features, facilitates transfusion-free cardiac surgery, even in complex neonatal procedures. Although some patients required transfusions during the further clinical course, we believe that this strategy might effectively contribute to an overall reduction in the number of patients

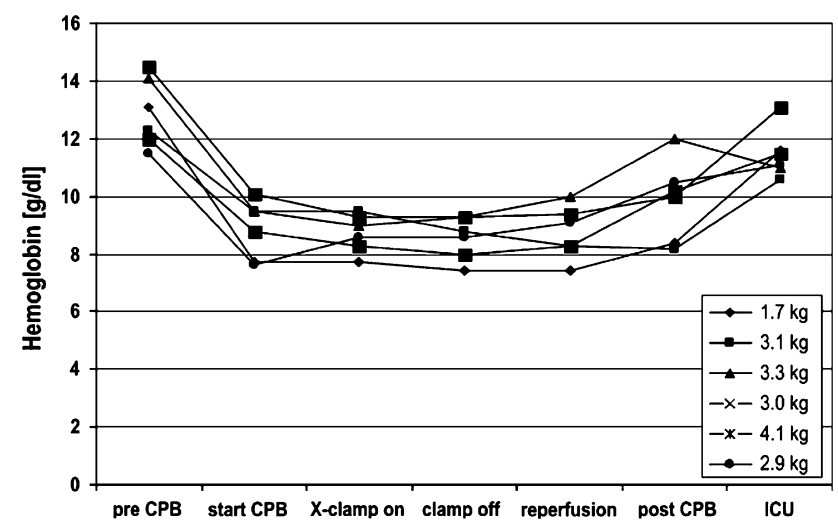

FIGURE 2. Course of hemoglobin values in patients without transfusions. $C P B$, Cardiopulmonary bypass; $X$-clamp, crossclamp; $I C U$, intensive care unit. 
requiring any transfusion and in the total number of foreign donor blood exposures.

We thank Anne Gale for editorial assistance.

\section{References}

1. Leal-Noval SR, Rincon-Ferrari MD, Garcia-Curiel A, et al. Transfusion of blood components and postoperative infection in patients undergoing cardiac surgery. Chest. 2001;119:1461-8.

2. Rogers MA, Blumberg N, Saint SK, et al. Allogenic blood transfusions explain increased mortality in woman after coronary artery bypass graft surgery. Am Heart $J$. 2006; 152:1028-34.

3. Lacroix J, Hebert PC, Hutchinson JS, et al. Transfusion strategies for patients in pediatric intensive care units. N Engl J Med. 2007;356:1609-19.
4. Boettcher W, Merkle F, Huebler M, et al. Transfusion-free cardiopulmonary bypass in Jehovah's Witness patients weighing less than $5 \mathrm{~kg}$. J Extra Corpor Technol. 2005;37:282-5.

5. Redlin M, Koster A, Huebler M, et al. Regional differences in tissue oxygenation during cardiopulmonary bypass for correction of congenital heart disease in neonates and small infants: relevance of near-infrared spectroscopy. J Thorac Cardiovasc Surg. 2008;136:962-7.

6. Golab HD, Takkenberg JJM, Gerner-Weelink GL, et al. Effects of cardiopulmonary bypass circuit reduction and residual volume salvage on allogenic transfusion requirements in infants undergoing cardiac surgery. Interact Cardiovasc Thorac Surg. 2007;6:335-9.

7. Kotani O, Honjo O, Nakakura M, et al. Impact of miniaturization of cardiopulmonary bypass on blood transfusion requirements in neonatal open heart surgery. ASAIO J. 2007;53:662-5.

\section{A novel technique for treatment of mitral valve prolapse/flail}

Goran Panic, MD, Miljko Ristic, MD, PhD, Svetozar Putnik, MD, Dejan Markovic, MD, Ivan Divac, MD, and Uros U. Babic, MD, PhD, Belgrade, Serbia

Mitral valve repair with artificial chordae is a widely accepted procedure for the majority of patients with degenerative mitral regurgitation (MR), rendering good long-term results. ${ }^{1}$ A new technique for the treatment of extensive mitral prolapse/flail is described herein.

\section{CLINICAL SUMMARY}

After median sternotomy, cardiopulmonary bypass is established between the right atrium and the aorta. The pericardium is opened, and the apex is elevated with stay sutures. A purse-string suture is placed onto the posterior aspect of the left ventricular (LV) apex. The LV apex is punctured with the Seldinger technique through the string suture, and an $8 \mathrm{~F}$ introducer sheath is placed into the LV cavity. After cross-clamping of the aorta and normothermic cardioplegia, the left atrium (LA) is opened in the usual manner. Two double-armed pledgeted 2-0 Prolene sutures (Ethicon, Somerville, NJ) are passed through the prolapsed/flail leaflet segment and traversed through the LV sheath out of the left ventricle. The heart is deaired, the LA is closed, and

From the Department of Cardiac Surgery, Institute for Cardiovascular Diseases, Clinical Center of Serbia, Belgrade, Serbia.

Received for publication July 4, 2008; revisions received Aug 9, 2008; accepted for publication Aug 15, 2008.

Address for reprints: Goran Panic, MD, Department of Cardiac Surgery, Institute for Cardiovascular Diseases Clinical Center of Serbia, Belgrade, 11000 Serbia (E-mail: bsanja@Eunet.yu).

J Thorac Cardiovasc Surg 2009;137:1568-70

$0022-5223 / \$ 36.00$

Copyright (c) 2009 by The American Association for Thoracic Surgery doi:10.1016/j.jtcvs.2008.08.029 the aortic crossclamp is removed. A custom-made polymer elastic tube of premeasured length and a 2-mm external profile is advanced over the exteriorized suture arms to contact the target leaflet, thereby securing the suture loops to the leaflet on the beating heart and thus replacing intracardiac knotting (Figure 1A). The introducer sheath is removed, and the LV entry site is closed with a custom-made polymer occluder placed over the suture arms. The sutures are pulled and released until a good coaptation of the prolapsed/flail segment is achieved on the beating heart with transesophageal echocardiographic (TEE) guidance (Figure 1B). The exteriorized suture lengths are locked with the separate loop knot and secured to the exterior of the myocardial entry site occluder (Figure 2).

Between March and December 2007, 6 male patients aged 64 to 73 years with extensive prolapse, flail, or both of the posterior $(n=4)$ and anterior $(n=2)$ mitral leaflets underwent mitral repair with the described procedure. All 6 patients had significant heart failure (New York Heart Association class III-IV) caused by severe MR 2 to 6 weeks before surgical intervention. Degenerative mitral disease was present in all, although only 1 patient had concomitant coronary artery disease treated with percutaneous intervention. The mitral annulus and the LA were not significantly enlarged in any of the patients. Informed consent was obtained from each patient. The procedure was approved by the institutional review board. No other interventions were performed during the operation. Cardiopulmonary bypass time ranged from 40 to 70 minutes, and aortic cross-clamp time ranged from 5 to 15 minutes. MR was abolished in 2 